Acta Crystallographica Section E

Structure Reports

Online

ISSN 1600-5368

\title{
Methyl 3-(cyclopropylmethoxy)-4-
} hydroxybenzoate. Corrigendum

\section{Jing-Jing Hou, Xian-Chao Cheng, Run-Ling Wang* and Shu-Qing Wang}

School of Pharmacy, Tianjin Medical University, Tianjin 300070, People's Republic of China

Correspondence e-mail: wangrunling2008@yahoo.cn

Received 1 December 2010; accepted 1 December 2010

The chemical diagram and the title of the paper by Hou et al. [Acta Cryst. (2010), E66, o2004] are corrected.

In the paper by Hou et al. (2010), the chemical name given in the Title should be 'Methyl 4-(cyclopropylmethoxy)3-hydroxybenzoate'. The revised scheme is shown below.

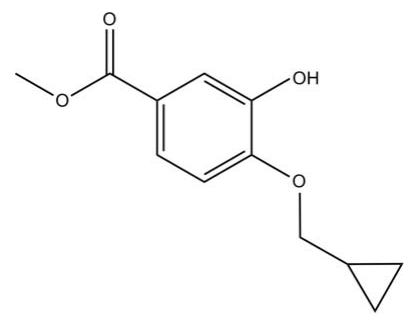

\section{References}

Hou, J.-J., Cheng, X.-C., Wang, R.-L. \& Wang, S.-Q. (2010). Acta Cryst. E66, o2004. 